\title{
Rehydration Quickly Assembles Photosynthetic Complexes in Desiccation Tolerant Riccia gangetica
}

\author{
Upma Bhatt, Hanwant Singh, Deepak Kumar and Vineet Soni* \\ Plant Bioenergetics \& Biotechnology Laboratory, Department of Botany, Mohanlal Sukhadia University, India \\ *Corresponding author: Vineet Soni, Plant Bioenergetics \& Biotechnology Laboratory, India
}

\section{ARTICLE INFO}

Received: 慧 August 25, 2020

Published: 慧 September 04, 2020

Citation: Upma Bhatt, Hanwant Singh, Deepak Kumar, Vineet Soni. Rehydration Quickly Assembles Photosynthetic Complexes in Desiccation Tolerant Riccia Gangetica. Biomed J Sci \& Tech Res 30(1)2020. BJSTR. MS.ID.004891.

Keywords: Desiccation; Riccia Gangetica; Chlorophyll fluorescence; JIP test

\section{ABSTRACT}

Resurrection plants such as lichens and some bryophytes have remarkable ability to survive under desiccation. At this stage no water content remains in the plant cellular system, but upon rehydration these plants subsequently regain their normal metabolism within seconds or minutes. To understand the physiological strategies of desiccation tolerance and hydration-induced photosynthetic recovery, we studied the polyphasic chlorophyll $a$ fluorescence OJIP kinetics in Riccia gangetica during desiccation and wellhydrated states. Fv/Fm (maximal quantum efficiency of PSII) of desiccated thallus was found 0.047 , which increased upto 0.79 within $24 \mathrm{~h}$ of rehydration. Similarly, rehydration remarkably induced the light harvesting efficiency and rate of electron transport in $R$. gangetica. Results of present studies reveal that $R$. gangetica has high ability to survive under desiccation phase and quickly recover the photosynthetic process upon rehydration through the activation of light harvesting complexes, and coversion of inactive PS II into functional state.
\end{abstract}

\section{Introduction}
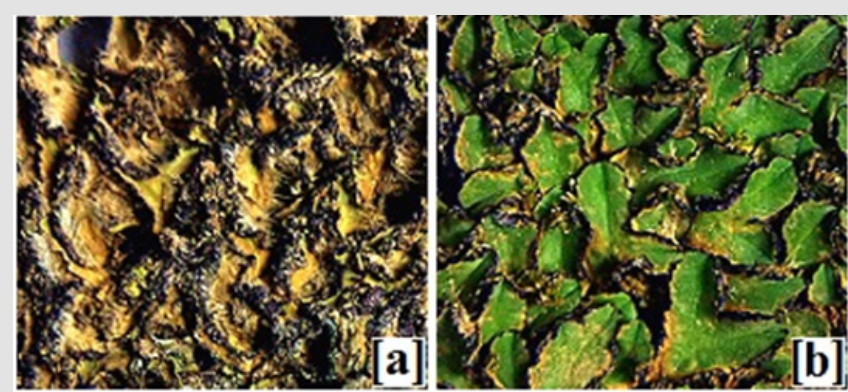

Figure 1:

a. Riccia gangetica in desiccated state, and

b. After $24 \mathrm{~h}$ of rehydration

Desiccation tolerance is a unique potential of lichens and some bryophytes [1]. The idea of a repair-based mechanism of desiccation tolerance in bryophytes was introduced by Bewley [2]. Riccia gangetica (Ricciaceae) has physiological and biochemical adaption to equilibrate their cellular water levels with atmospheric water levels, a trait known as poikilohydry. At desiccated stage, the thalli of $R$. gangetica appear to be dead-brown, dried and lifeless (Figure 1a). Traces of water rapidly activate the photosynthetic process (Figure 1b). Hydration induced quick activation of photosynthesis indicates that all components of light reaction and enzymes are preserved throughout the events of desiccation. JIP test based on polyphasic chlorophyll $a$ fluorescence analysis has become one of the powerful tools to study survival strategies in lichens and bryophytes $[3,4]$. In present investigations, efforts were done to answer the following questions

a. How the photosynthetic machinery is preserved in desiccated R. gangetica?, and

b. How rehydration reactivates the photosynthetic process in desicatted thallus withinseconds or minutes? To answer these questions, polyphasic chlorophyll fluorescence OJIP kinetics were studied during desiccation and rehydration process in R. gangetica.

\section{Materials and Methods}

Plant Materials \& Measurement of Polyphasic Chlorophyll Fluorescence Kinetics: Dehydrated thalli of $R$. gangetica were collected from botanical garden, University College of Science, Udaipur (India) during rainy season (August, 2019). The Chlorophyll $a$ fluorescence parameter $\left(\mathrm{F}_{0}\right.$-minimum fluorescence, $\mathrm{F}_{\mathrm{M}}-$ minimal 
fluorescence) were measured by HandyPEA (HansaTech, UK) according to the JIP- test $[3,4]$. The leaf clip (HansaTech, UK) was modified so as to facilitate the addition of water from the back side even during multiple light pulse measurements. Prior to hydration, $\mathrm{F}_{0}$-minimum fluorescence, and $\mathrm{F}_{\mathrm{M}}$ - minimal fluorescence of desiccated thalli were recorded (Tables $1 \& 2$ ). Upon hydration, fluorescence transient 0 -J-I-P were recorded at $5 \mathrm{Sec}, 1 \mathrm{~h}$ and $24 \mathrm{~h}$. The phenomenological energy fluxes (Absorption flux per cross section-ABS/CS, trapped energy flux per cross section-TR/CS, and electron transport flux per cross section -ET/CS), the density of active PS II reaction center (RI/CS), quantum yield of primary photochemistry $\left(\mathrm{F}_{\mathrm{V}} / \mathrm{F}_{\mathrm{M}}-\varphi_{\mathrm{po}}\right)$, quantum yield of electron transport ET/ABS $\left(\varphi_{\mathrm{E} 0}\right)$, quantum yield of energy dissipation $\left(\phi_{\mathrm{DO}_{0}}\right)$ were calculated as per the equations of JIP- test [3]

Table 1: Data extracted from the recorded fluorescence transient O-J-I-P.

Data extracted from the Recorded Fluorescence Transient 0-J-I-P

$$
\begin{gathered}
F_{0} \cong F_{50 \mu \mathrm{s}} \\
F_{\mathrm{m}}=F_{\mathrm{P}}
\end{gathered}
$$

Table 2: Data extracted from the recorded fluorescence transient O-J-I-P.

\begin{tabular}{|c|c|}
\hline \multicolumn{2}{|c|}{ Phenomenological Energy Fluxes (Per Excited Cross Section - CS) } \\
\hline $\begin{array}{c}\text { ABS /CS- Absorption flux per cross } \\
\text { section }\end{array}$ & $\mathrm{F}_{0}$ \\
\hline $\begin{array}{c}\text { TR } / \text { CS- trapped energy flux per cross } \\
\text { section }\end{array}$ & $\mathrm{j}_{\mathrm{P}_{0}} \mathrm{x}(\mathrm{ABS} / \mathrm{CS})$ \\
\hline $\begin{array}{c}\text { ET / CS- electron transport flux per cross } \\
\text { section }\end{array}$ & $\mathrm{j}_{\mathrm{P}_{\mathrm{O}}} \times \mathrm{y}_{0} \mathrm{x}(\mathrm{ABS} / \mathrm{CS})$ \\
\hline
\end{tabular}

Performance Index on Cross Section Basis ${ }^{P I_{C S}}=\frac{A B S}{C S} \times \frac{1-\left(F_{0} / F_{u}\right)}{M_{0} / V_{J}} \times \frac{F_{u}-F_{0}}{F_{0}} \times \frac{1-V_{J}}{V_{J}}$

\section{Results and Discussion}

Desiccation-tolerance, the skill to survive without water for longer period and then recover normal metabolic activity upon rehydration, is one of the most remarkable features of bryophytes. This ability to survive under desiccation has also been observed in lichens and bryophytes [3,4]. In this study, we chose the $R$. gangetica, one of the dominant bryophytes of Rajasthan (India), to investigate the mechanism of conservation of photosynthetic potential under desiccation and rapid recovery of photosynthesis upon rehydration. Desiccated thalli did not show any variation between $\mathrm{F}_{0}$ and $\mathrm{F}_{\mathrm{M}}$, which shows complete inactivation of photosynthetic activity (Figure 2). A quick induction in chlorophyll fluorescence was noticed when desiccated thalli were hydrated. Chlorophyll a fluorescence increased continuously from initial $\left(\mathrm{F}_{0}\right)$ to maximal $\left(\mathrm{F}_{\mathrm{M}}\right)$ intensity in after 5 seconds of watering (Tables 3 \& 4). Two intermediate peaks $\mathrm{F}_{\mathrm{J}}$ (chlorophyll fluorescence at $2 \mathrm{~ms}$ ) and $\mathrm{F}_{\mathrm{I}}$ (chlorophyll fluorescence at $300 \mathrm{~ms}$ ) were formed between $\mathrm{F}_{0}$ and $\mathrm{F}_{\mathrm{M}}$, forming a typical OJIP curve. Rapid increase in fluorescence indicates quick recovery of photosynthetic machinery in R. gangetica.

Table 3: Density of reaction centers

\begin{tabular}{|c|c|}
\hline \multicolumn{2}{|c|}{ Density of Reaction Centers } \\
\hline $\begin{array}{c}\text { RC/CS }=\phi_{\mathrm{Po}} \cdot\left(V_{\mathrm{J}} / M_{0}\right) \cdot \\
\mathrm{ABS} / \mathrm{CS}\end{array}$ & $\begin{array}{c}\text { Density of reaction centers }\left(Q_{\mathrm{A}} \text {-reducing PSII }\right. \\
\text { reaction centers })\end{array}$ \\
\hline
\end{tabular}

Table 4: Quantum efficiencies or flux ratios.

\begin{tabular}{|c|c|}
\hline \multicolumn{2}{|c|}{ Quantum Efficiencies or Flux Ratios } \\
\hline $\mathrm{j}_{\mathrm{Po}_{\mathrm{o}}}$ or TR / ABS or $\mathrm{F}_{\mathrm{V}}$ & Quantum yield of primary photochemistry \\
\hline$/ \mathrm{F}_{\mathrm{M}}$ & Quantum yield of electron transport \\
\hline$\phi_{\mathrm{Eo}}$ or ET / ABS & Quantum yield of energy dissipation \\
\hline$\phi_{\mathrm{Do}}$ or DI / ABS & Qun \\
\hline
\end{tabular}

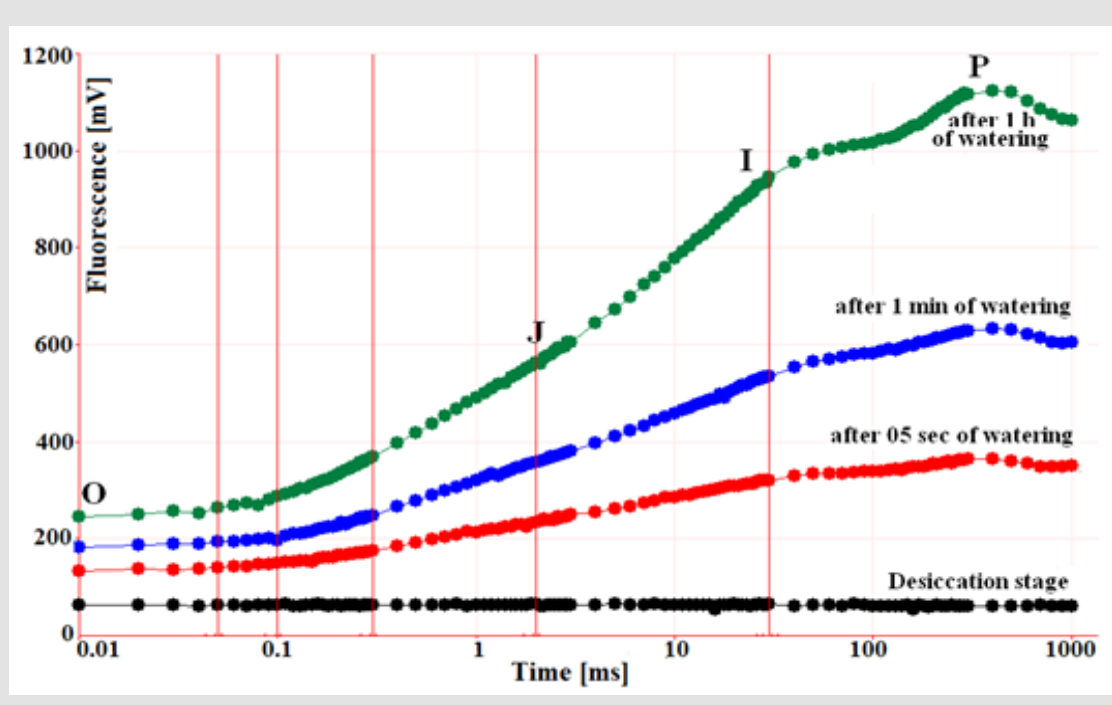

Figure 2: Induction of chlorophyll a fluorescence during desiccation and rehydration stage in R. gangetica. 
$\mathrm{Fv} / \mathrm{F}_{\mathrm{M}}\left(\mathrm{j}_{\mathrm{P}_{\mathrm{o}}}\right.$ or $\left.\mathrm{TR} / \mathrm{ABS}\right)$ is a sensitive indicator of plant photosynthetic performance. Lower values of Fv/Fm indicates down-regulation of photosynthesis in plants (Maxwell \& Johnson 2000). Upon rehydration, Fv/Fm apparently increased from 0.047 (desiccated state) to 0.79 (24h after rehydration). Increase of Fv/ Fm indicates that the thalli have remarkable ability to restore photosynthetic performance by the activation of light harvesting complexes and other proteins/enzymes involved in photosynthesis process. Similarly, quantum yield of electron transport $\left(\phi_{\mathrm{Eo}}\right.$ or ET / ABS) increased with increasing the duration of hydration upto $24 \mathrm{~h}$. A drastic decline in quantum yield of energy dissipation $\left(\phi_{\mathrm{Do}_{0}}\right.$ or DI / ABS) indicates the utilization of light energy into electron transport process (Figure 3a).

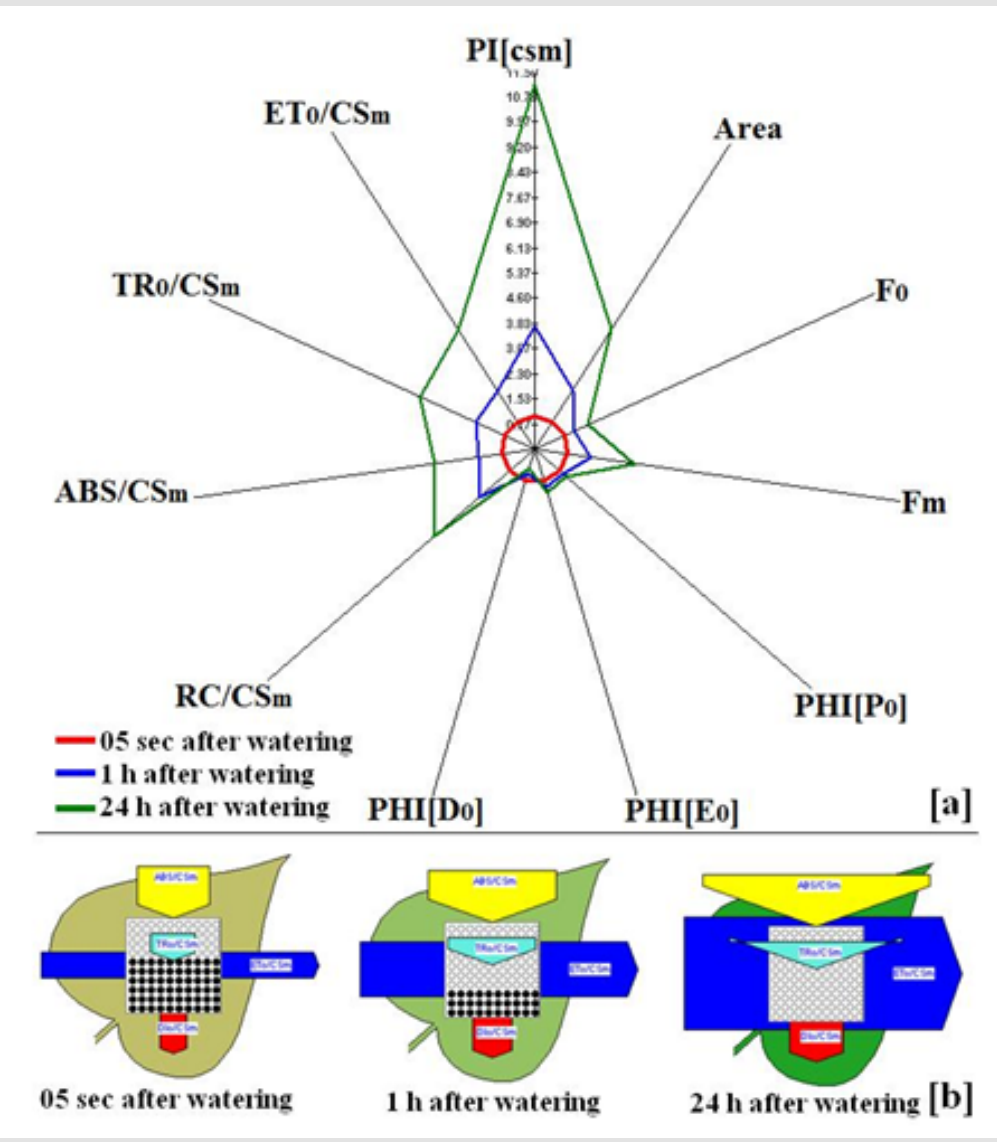

Figure 3:

a. Radar plot and

b. leaf modelsshowing the variations in photosynthetic parameters during desiccation and various rehydration stages in $R$. gangetica(black dots are representing inactive PSII RCs and intensity of leaf color is indicating chlorophyll concentration).

Density of active reaction (RC/CS) centers increased upon rehydration (inactive RCs are denoted by black dots in leaf model of desiccated thallus in Figure $3 \mathrm{~b}$ ). Increase in $\mathrm{RC} / \mathrm{CS}$ is due to the conversion of inactive PSIIs into functional state. Absorbance per cross section (ABS/CS) rapidly increased during rehydration process. It may be due to the quick assembly of light harvesting complexes (LHCs). Trapping (TR/CS) and electron transport per cross section (ET/CS) also enhanced when desiccated thalli were rehydrated (Figure 3b). Increment in TR/CS and ET/CS suggests that rehydration converts inactive PSII reaction centers into active forms. Performance indices provide information about the overall photosynthetic performance of PSI and PSII. In present studies, rehydration rapidly increased the performance index (PIcs) in $R$. gangetica. On the basis of all photosynthetic parameters, it is concluded that $R$. gangetica has evolved a remarkable physiological adaption to protect their photosynthetic machinery under desiccation stage. The results also indicates that during desiccation PS II reaction centers become inactive and act as 'energy dissipating units', while they converts in 'energy utilizing units' upon rehydration.

\section{References}

1. Gao B, Li X, Zhang D, Liang Y, Yang H, et al. (2017) Desiccation tolerance in bryophytes: The dehydration and rehydration transcriptomes in the desiccation-tolerant bryophyte Bryum argenteum. Sci Rep 7: 7571. 
2. Bewley JD (1979) Physiological aspects of desiccation tolerance. Annu Rev Plant Physiol 30: 195-238.

3. Heber U, Soni V, Strasser RJ (2011) Photoprotection of reaction centers: thermal dissipation of absorbed light energy vs charge separation in lichens. Physiol Plant 142(1): 65-78.

\section{ISSN: 2574-1241}

DOI: 10.26717/BJSTR.2020.30.004891

Vineet Soni. Biomed J Sci \& Tech Res

(C) (P) This work is licensed under Creative

Submission Link: https://biomedres.us/submit-manuscript.php
4. Bhatt U, Singh H, Kumar D, Soni V (2019) Rehydration Induces Quick Recovery of Photosynthesis in Desiccation Tolerant Moss Semibarbula orientalis. J Pl Sci Res 35(2): 183-187.

$\begin{array}{ll}\text { BIOMEDICAL } & \text { Assets of Publishing with us } \\ \text { RESEARCHES } & \text { - Global archiving of articles } \\ \text { - Immediate, unrestricted online access }\end{array}$

